\title{
Формальные и семантические сближения в сфере русско-польской межъязыковой омонимии
}

\author{
Structural and semantic relationships in the area \\ of Russian-Polish interlingual homonymy
}

\begin{abstract}
This article deals with the issue of structural and semantic relationships in the area of Russian-Polish interlingual homonymy, such as exclusion, inclusion, and hybridization. The analysis of Russian-Polish homonymous doublets made it possible to specify two basic reasons for the differences in meaning of the lexemes in both languages: semantic divergence of the words with a common etymon (disintegration of polysemy) and phonetic convergence. The study revealed that interlanguage Russian-Polish correspondences with a partial coincidence of lexical meanings make up the largest group of interlanguage homo-pairs. The types of semantic relations described at the word level do not exhaust the variety of semantic relations between Russian-Polish interlanguage homonyms. The depth of meaning development is another theoretical problem of modern lexicology and lexicography. In addition to the semantic differences between Russian-Polish homo-pairs, there may be more complex relationships. They are observed in cases where stylistic and functional discrepancies are layered on semantic inconsistencies. The differences in pragmatic significance are the most significant and can form the subject of independent study.
\end{abstract}

Keywords: interlingual homonymy, interlingual contacts, semantic divergence, phonetic convergence, semantic relationships

Krzysztof Kusal, Akademia Humanistyczno-Ekonomiczna w Łodzi, Łódź - Polska, christofor49@ mail.ru, ORCID ID: https://orcid.org/0000-0003-0409-5396

1. Омонимия как универсальное языковое явление не ограничивается системой одного языка и, выходя за его пределы, становится межъязыковым явлением. Внутриязыковая омонимия, возникновение которой связано с историческим взаимодействием общеславянских морфем, может превратиться в межъязыковую при соответствующем семантическом размежевании (дивергенции) созвучных слов с одним и тем же общеславянским формантом.

Настоящая статья посвящена характеристике формальных и семантических реляций в сфере русско-польской межъязыковой омонимии. Анализ 
русско-польских омопар показал, что характер семантических отношений между лексемами двух языков может быть квалифицирован либо как полное семантическое различие (отношение исключения, т. е. дизъюнкция), либо как частичное (отношения семантического включения и пересечения).

Анализ внутриязыковых и межъязыковых омонимов в плане выражения (далее ПВ) предполагает определение их фонетической, морфологической и/или графической близости. Соотношение формальных признаков, как для внутриязыковых, так и межъязыковых омонимов, можно представить с помощью логической формулы $\mathbf{F}=\mathbf{A U B}$, где $\mathbf{F}$ - формальное тождество, $\mathbf{A}$ - фонетическое тождество, B - графическое, а знак $\mathbf{U}$ указывает на отношение слабой дизъюнкции и/или (Malahovskij 35). В различных видах омонимии (внутриязыковой и межъязыковой) могут иметь место:

- отношения типа А (таковы, например, омофоны в русском языке: костный - косный, пруд - прут; ср. также межъязыковые русско-польские омофоны: лестный - leśny, властный - własny и под. (ср. Zinkevič; Karpov).

- отношения типа В (русские омографы мука - мука; межъязыковые русско-польские омографы: русск. запаx 'заход одной полы за другую' - пол. zapach (равное по семантике русскому запаx - 'свойство предметов, веществ, воспринимаемых обонянием’); ср. также маяк majak, чулкㄴ $-c z \underline{u} t k i, y c m \underline{a}-\underline{u s t a}$ и под.

- соотношение формальных признаков и в сфере внутриязыковой и межъязыковой омонимии может быть выражено одновременно двумя способами - фонетическим тождеством (A) и графическим тождеством (В) (ср. русские слова колоть 'раздроблять' и колоть от укол, ветрянка 'оспа' и ветрянка 'мельница'. Аналогичны соотношения межьязыковых русско-польских омонимов: русск. лук 'овощное растение с трубчатыми листьями и луковицей' и пол. $t u k$ 'ручное орудие для метания стрел', русск. засада ед.ч. 'скрытое расположение кого-нибудь' и пол. zasada ед. ч. 'основание, начало', уймa - ијта, плётка plotka и под.

Приведенные примеры наглядно демонстрируют основу для классификации различных типов внутриязыковых и межъязыковых омонимов в ПВ. Четкое представление о внешней структуре как внутриязыковых, так и межъязыковых омонимов дает классификация, предложенная Владимиром Лейчиком (см. Lejčik 133-145), а также схемы анализа плана выражения слов-омонимов, используемые в работах Льва Малаховского и Владимира Дубичинского (см.: Malahovskij; Dubičinskij) на русско-английском языковом материале. Названные схемы принимаются в данной работе с некоторыми дополнениями и коррективами. Это связано с тем, что при анализе 
языков близкородственных весьма важен учет фонетических особенностей каждого из сравниваемых языков.

Наше исследование показало, что подобный подход необходим для отражения в классификации тех нюансов звучащей речи, которые связаны со своеобразием произношения отдельных гласных и согласных в различных их сочетаниях и позиционных условиях. Под формальным сопоставлением лексем двух или более языков подразумевается их сравнение по следующим показателям: 1) фонемный состав, 2) написание, 3) морфемный состав, 4) акцентологическая характеристика.

Исходя из вышесказанного, говоря о формальном соответствии русских и польских слов, мы будем иметь в виду:

- во-первых, отношения формального тождества (в тех случаях, когда лексемы двух языков совпадают по одному или обоим, то есть и по фонетическому, и по графическому признакам ПВ) практически во всех формах;

- во-вторых, отношения частичного формального тождества (при совпадении звучания и/или написания части словоформ межъязыковых соответствий).

Для того, чтобы наглядно продемонстрировать допустимые пределы варьирования межъязыковых омонимов в ПВ (в системе знаменательных частей речи русского и польского языков), в работе предлагается следующая классификация межъязыковых омонимов, предусматривающая выделение трех основных типов: фонетико-графические, графические и фонетические (cp. Malahovskij 70-71). В данной статье дается общая характеристика межъязыковых русско-польских омонимов в ПВ с комментариями фонетических особенностей русского и польского языков. Итак,

1.1. Фонетико-графические межъязыковые омонимы характеризуются: а) полным совпадением в ПВ (в звучании и написании) исходной формы и большинства словоформ, то есть соотношением формальных признаков по формуле $\mathbf{F}=\mathbf{A U B}$. Например, русск. баня 1) 'специальное помещение, где моются и парятся', 2) разг. перен. 'взбучка, строгий выговор, нагоняй' и пол. bania 1) 'выпуклая крыша, свод в виде полушария; купол'; 2) жарг. 'голова'.

Вместе с тем, как видно из примера, и в данном случае мы не можем говорить об абсолютном формальном тождестве, так как особенностью вокализма польского языка (в сравнении с русским языком) является то, что польскому вокализму не известно такое фонетическое явление, как аканье. На этом основании приведенные выше пары русско-польских омонимов (в сфере наречий) выделены нами в особую разновидность фонетико-графических межъязыковых омонимов: разом - razem, огулом - ogółem, лихо - licho и под., б) с незначительными различиями в звучании гласных 
фонем. Таковы и омонимичные соответствия русск. потрава и пол. potrawa, подачка - padaczka, дробина - drabina и ряд других.

При восприятии речи билингвом подобные „тонкие” произносительные различия, как правило, нивелируются, становятся малосущественными либо несущественными. Аналогичные (при восприятии речи билингвом) часто нивелируемые фонетические различия наблюдаем также в русско-польских соответствиях типа: гонор - honor, гулять - hulać, чинный-czynny, бесnечный - bezpieczny и др.

В приведенных примерах фонемы [г] и [ч] русского языка соответствуют фонемам [x] и [с̌] польского языка, но польская [x] является заднеязычным фрикативным, а [ч] - всегда твердой (Kusal 1998: 40-41, 45).

Из сказанного очевидно, что, даже при наличии двух формальных признаков омонимии - фонетического и графического тождества означающих, существуют определенные нюансы в произношении, которые позволяют говорить лишь об относительном формальном (в ПВ) тождестве омонимичных лексем двух языков. В этом заключается, на наш взгляд, специфика данной разновидности фонетико-графических межъязыковых омонимов, их отличие от фонетико-графических омонимов в рамках какой-либо отдельной конкретной внутриязыковой омонимической группы

1.2. В разряд фонетических межъязыковых омонимов включаются слова с регулярными расхождениями графем, например, noтpaвa - potrawa, попрать - рорrać и ряд других.

К фонетическим межъязыковым омонимам следует отнести также лексемы двух языков с графико-орфографическими различиями. Ср.: русск. властный 'склонный повелевать, не признающий права личности' и пол. wtasny 'принадлежащий по праву собственности кому-либо', а также лестныгй 'содержащий похвалу, одобрение' и leśny 'лесной'.

Подобные формальные расхождения в написании объясняются закономерными соответствиями графем и тем, что в польском языке явление упрощения групп согласных стн, здн, ндк, рди, лни, рнч, стл закреплено орфографией - serce, postać, późno и т. д.

1.3. Графические межъязыковые омонимы - это слова, совпадающие в написании, но различающиеся произношением. Графическое тождество лексем двух языков может быть:

a) результатом случайного совпадения слов, разных по происхождению. Например, рок - rok, морс - mors, халдa - hałda, кum - kit и под.;

б) результатом семантического и акцентологического расхождения этимологически тождественных слов типа русск. жалобный и пол. żałobny 'траурный; скорбный; похоронный'; аналогично: мотылль mótyl, намёт - namiot, забеz - zábieg и под.; 
в) результатом совпадения этимологически тождественных слов, различающихся произношением отдельных фонем. Ср.: русск. гадать, загон, уnоминать и пол. gadać, zagon, uротіпас́ и под.

Перечисленные типы межъязыковых омонимов вполне укладываются в логическую формулу F = AUB (см. Malahovskij), ибо наличия хотя бы одного из формальных признаков (при расхождении значений) достаточно для того, чтобы признать существование омонимичных отношений между сопоставляемыми лексемами. Именно в наличии формальных признаков тождества (с некоторыми нюансами при межъязыковой омонимии) проявляется, на наш взгляд, аналогия между явлениями внутриязыковой и межъязыковой омонимии.

2. Различия между категориями внутриязыковых и межъязыковых омонимов проявляются также в сфере семантики, ибо межъязыковые закономерные омонимы, как отмечалось ранее, часто сохраняют некие общие семы либо лексико-семантические варианты (далее ЛСВ). В классификации типов семантических соответствий мы опирались на логическую схему возможных формально-смысловых соответствий между знаками: тождество, включение, пересечение и отсутствие общей части (ср. Lipczuk 390; Fedorčuk 14-15).

\section{1. Семантические отношения дизъюнкции (модель PUI)}

Данный тип отношений определяется отсутствием общей части в значениях русской и польской лексических единиц, если омонимия возникла случайно (в результате конвергенции). В закономерно возникших омонимах и однокорневых паронимах возможно сохранение следов прежней семантической связи.

2.1.1. Отношения полного семантического различия могут быть следствием расхождений этимологически тождественных слов.

Например, русское МЕШКАТЬ и польское MIESZKAĆ, восходящие к одному этимону (к глаголу мешать), на синхронном срезе имеют разные значения ${ }^{1}$ :

МЕШКАТЬ $n d k d k$, przest. posp. с чем

1. zwlekać, ociągać się z czym: Мешкать с работой. Ociągać się z robotą (z pracą). Мешкать с ответом, с отъездом. Zwlekać z odpowiedzią, z wyjazdem; ociągać się z odpowiedzią, z wyjazdem. Здравствуй, что ты это так замешкал? Witaj, czemu tak zamarudziłeś? 2. zatrzymywać się: Лиза шла впереди (...)

1 Здесь и далее весь иллюстративный материал приводится по Русско-польскому словарю межъязыковых омонимов (Kusal 2002). 
и мешкала у каждого встречного предмета. Liza szła przodem i zatrzymywała się koło każdego mijanego przedmiotu.

MIESZKAĆ несов.

жить, проживать (ofic.); обитать: Mieszkać na pierwszym piętrze. Жить (проживать) на первом этаже. Mieszkać w centrum miasta. Проживать в центре города. Mieszkać pod jednym dachem. Жить под одной крышей. Możesz zamieszkać u nas. Можешь поселиться (остановиться) у нас. $\diamond$ Mieszkać, zamieszkać kątem. $\diamond$ Снимать, снять угол.

Аналогичный пример: русск. ЗАПРОСИ'ТЬ 1) 'сделать запрос, затребовать что-либо официально’; 2) разг. назвать первоначальную цену за вещь или работу' и пол. ZAPROSIĆ 'пригласить' происходят от древнерусского ЗАПРОШАТИ - 'просить'. В современном польском языке сема 'просьба' является ядерной для лексемы ZAPROSIĆ ‘попросить прибыть куда-либо; пригласить, позвать'. Ср.:

\section{ЗАПРОСИТЬ $d k$}

1. кого-что о чем ofic. zapytać kogo o co, skierować pytanie, zwrócić się z pytaniem do kogo, zasięgnąć czego: Запросить мнение редакции. Zapytać (poprosić) o opinię (o zdanie) redakcji; zasięgnąć opinii redakcji. 2. чmo pot. zażądać: Запросить сто рублей. Zażądać sto rubli.

ZAPROSIĆ сов.

пригласить кого: Zaprosić znajomych, przyjaciół. Пригласить знакомых, друзей. Zaprosić na urodziny, na wesele. Пригласить на день рождения, на свадьбу. Zaprosić kogoś na wieś, na wakacje. Пригласить кого-л. в деревню, на каникулы.

В структуре значения русского глагола ЗАПРОСИТЬ ядерной семой является сема 'требование', сема же 'просьба' имеет здесь лишь вероятностный характер. В данном случае произошло переосмысление семантики общих по происхождению слов русского и польского языков. Однако и после семантических трансформаций значений у лексем сохранилась некоторые точки семантического соприкосновения: отнесенность к семантическому полю „волеизъявления”.

2.1.2. Расхождение семантики слов, восходящих к одному этимону, может быть связано и с расширением/сужением семантического объема лексемы в одном из языков. Указанные процессы привели к функционированию в русском и польском языках межъязыковых омонимов/паронимов двух типов:

1. Русское слово сохраняет былое, широкое, общеславянское значение слова, а польский аналог употребляется в более узком, частном значении. 
Например, русск. ЗЛОДЕЙ: 1) 'тот, кто совершает злодеяния или способен на них, преступник'; 2) употребляется как бранное слово; 3) устар. преступник; убийца и пол. ZŁODZIEJ 'тот, кто занимается вороством; вор, похититель'. Ср. контексты:

\section{ЗЛОДЕЙ $m$}

1. łotr, nikczemnik, łajdak, szubrawiec: Это был великий грешник и злодей. Był to wielki grzesznik i łotr. Какой-то злодей украл у меня в поезде чемодан. Jakiś szubrawiec (łajdak) ukradł mi w pociągu walizkę. 2. przest. przestępca, złoczyńca, zbrodniarz: В этой колонии полно убийц и прочих злодеев. W tym obozie jest (siedzi) pełno zabójców i innych złoczyńców (zbrodniarzy). 3. pot. obelż. żart. niegodziwiec, bezecnik; łobuz; hultaj: Ах ты, злодей! Ту łobuzie (łotrze, hultaju)!

\section{ZŁODZIEJ $\boldsymbol{M}$.}

вор: Złodziej kieszonkowy. Карманный вор. $\square$ Na złodzieju czapka gore. На воре шапка горит.

В русский язык в данном случае перешло большее количество значений древнерусского слова-прототипа по сравнению с польским.

2. Вторая группа слов противоположна по содержанию первой - польские слова обладают большим семантическим объемом, русские же соответствия употребляются в более узком, частном значении. Например: пол. ŁASKA 'милость, благосклонность; любезность; помилование; одолжение' и русск. ЛАСКА 'проявление нежности, любви':

\section{ЛАСКА $\dot{z}$}

1. pieszczota; czułość: Материнская ласка. Macierzyńska (matczyna) czułość (tkliwość, pieszczota). 2. życzliwość, serdeczność: Принимать с лаской кого-л. Przyjmować (podejmować) kogoś serdecznie (życzliwie). książk. Расточать ласки. Hojnie obdarzać (szafować, zaszczycać) życzliwością (serdecznością).

\section{ŁASKA}

1. милость, благосклонность; расположение: Вус́ w łaskach. Быть в милости. Zaskarbić sobie czyjąś łaskę. Снискать чьё-н. расположение. $\diamond$ Pozostać (zostać) na łasce losu; być zdanym na łaskę losu. $\diamond$ Быть брошенным (оставленным) на произвол судьбы. 2. любезность, одолжение; снисхождение: Zrobić komuś łaskę. Сделать кому-л. одолжение. $\diamond$ ирон. Nie łaska? Hе угодно (ли)? Не желаете (не хотите)? pot. Слабо'? $\diamond$ разг. Bez łaski. Обойдёмся, обойдусь (без чьей-л. помощи); сами справимся; сам справлюсь; сами с усами (zart.). 3. помилование: $\Delta$ Prawo łaski. $\Delta$ Право помилования. $\diamond \mathrm{W}$ drodze łaski. a) В порядке помилования; б) В виде (в порядке) исключения. 
Аналогично русск. ЩУ’ПЛЫЙ и пол. SZCZUPŁY:

ЩУ’ПЛЫЙ $m$

pot. wątly, mizerny, chuderlawy; niepokaźny, niepozorny: Щуплое детское тельце. Wątłe dziecięce ciałko. Щуплый человечек. Niepozorny człeczyna.

SZCZUPŁY $\boldsymbol{M}$.

1. худощавый, сухощавый, поджарый; тонкий; стройный: Szczupła dziewczyna; szczupły chłopak. Худенькая (стройная) девушка; худощавый (поджарый) парень. Szczupła sylwetka. Тонкая (стройная, худощавая) фигура. Szczupły w pasie. C тонкой талией. Szczupła twarz; o szczupłej twarzy. Худощавое лицо; с худощавым лицом. Szczupłe ramiona, ręce. Тонкие плечи, руки. 2. скудный; ограниченный; малочисленный: Szczupłe środki, zapasy, dochody. Скудные (ограниченные) средства, запасы, доходы. Szczupła racja żywnościowa. Скудный (небольшой) рацион. Szczupłe grono ludzi. Узкий круг людей.

2.1.3. Интересно семантически пересекаются русские и польские слова, восходящие к одному этимону и имеющие на синхронном срезе противоположные значения. Некоторые лингвисты рассматривают подобное явление как межъязыковую антонимию (см. Plotnikov) либо энантиосемию (Balalykina).

Наиболее показательны в этом плане русско-польские омопары: ВОНь 'дурной запах'/WOŃ ‘запах, аромат' и УРОДЛИВЫЙ ‘безобразный'/URODZIWY 'красивый’ (ср. польск. uroda 'красота'):

$\mathrm{BOHb} \dot{z}$

smród, fetor: Удушливая вонь. Duszący fetor.

WOŃ ж.

запах, аромат: Woń kwiatów. Запах, аромат цветов. Woń perfum. Аромат духов.

\section{УРО'ДЛИВЫЙ $m$}

1. pejor. ułomny, kaleki, zniekształcony, pokraczny, koślawy: Уродливое существо. Ułomna (pokraczna) istota. Уродливый ноготь. Zniekształcony (zdeformowany) paznokieć. Уродливые деревья, ветви. Powykręcane (koślawe, pokracznie zdeformowane) drzewa, gałęzie. 2. pejor. szpetny, szkaradny; wstrętny: Уродливый наряд. Szkaradny strój. Уродливая внешность. Szpetny (pokraczny, szkaradny, ohydny) wygląd. 3. przen. pejor. spaczony, wypaczony; nieprawidłowy: Уродливое воспитание. Spaczone (nieprawidłowe) wychowanie. Уродливый вкус. Wypaczony gust. Уродливые мысли. Wypaczone myśli. 
URODZIWY $\boldsymbol{M}$.

одобр. красивый; прекрасный; хорош собою; отборный: Urodziwy chłopiec. Красивый юноша; красавец-юноша. Urodziwa panna. Красивая (прекрасная) девушка (барышня). Urodziwe jabłka, pomidory. Отборные яблоки, помидоры.

Ср. также омопару МЛАДЕНЕЦ ‘дитя, ребенок'/MŁODZIENIEC 'молодой человек, юноша':

\section{МЛАДЕ'НЕЦ $m$}

małe dziecko; dziecię; dzieciątko: Новорожденный младенец. Noworodek. Грудной младенец. Niemowlę, osesek. $\diamond$ Избиение младенцев. $\diamond$ Rzeź niewiniątek.

\section{MŁODZIENIEC $\boldsymbol{\mu}$.}

юноша; молодой человек: Przystojny młodzieniec. Симпатичный юноша.

Случаи таких резких антонимичных различий генетических коррелятов свидетельствуют о глубоких изменениях, которым подверглись эти некогда тождественные слова в процессе исторического формирования и развития лексических систем славянских языков. Однако семантическое сближение формально сходных русских и польских слов возможно даже при расхождении значений. Этому способствует наличие у анализируемых лексем некоторых общих смысловых элементов (например, сема 'внешность' у пары русск. УРОДЛИВЫЙ - укр. ВРОДЛИВИЙ - пол. URODZIWY).

2.1.4. Семантические отношения дизъюнкции могут быть обусловлены внутриязыковой омонимией. Например, русск. БРАК I 'супружеские отношения, законно оформленные'; БРАК II 'недоброкачественные, с изъяном предметы производства'; 'изъян, повреждение' и пол. BRAK - 'нехватка, недостаток чего-либо, отсутствие кого-, чего-либо’:

БРАК I $m$

ślub, małżeństwo: Состоять в браке. Pozostawać w związku małżeńskim. Вступить в брак. Zawrzeć związek małżeński. Свидетельство о браке. Akt, świadectwo ślubu.

БРАК II $m$

skaza, wada, usterka, defekt; brak: Товар с браком. Towar wybrakowany.

$\operatorname{BRAK} \boldsymbol{M}$.

1. в знач. сказ. безл. не хватает, недостает; нет(у): Brak czasu. Не хватает времени. Brak [mi] słów. Слов не хватает. 2. недостаток, нехватка; отсутствие; пробел: Brak środków, doświadczenia. Недостаток (отсутствие) средств, опыта. Braki w wykształceniu. Пробелы в образовании. $\diamond \mathrm{Z}$ braku, w braku czego. Ввиду отсутствия чего-л. 
Аналогично: пол. CELNY I 'меткий', CELNY II 'превосходный; отборный', CELNY III 'таможенный’ и русск. ЦЕЛЬНЫЙ 1. состоящий из одного вещества, куска; сплошной; 2. не разбавленный; 3. целостный:

ЦЕ'ЛЬНЫЙ $m$

1. monolitowy, ciągły: Цельный гранит. Monolit granitu. Из цельного куска. Z jednego kawałka; z jednej bryły. 2. nierozcieńczony: Цельное вино. Nierozcieńczone wino. Цельное молоко. Mleko pełnotłuste (pełne, nie odciągane). 3. harmonijny, zwarty; jednolity; ukończony: Цельное впечатление. Jednolite wrażenie. przen. Цельный характер. Stały charakter. Цельное произведение. Zwarty (spójny) utwór. В его альбоме не было ни одного цельного наброска. W jego albumie nie było (w swoim albumie nie miał) ani jednego ukończonego (dokończonego) szkicu.

CELNY I $M$.

меткий: Celny strzał, rzut. Меткий выстрел, бросок. Celny strzelec. Меткий стрелок. перен. Celne określenie. Меткое определение. перен. Celna uwaga. Меткое замечание.

CELNY II $M$.

1. книжн. превосходный, отличный, замечательный; выдающийся: Celna proza. Замечательная проза. Celne dzieło. Выдающееся (замечательное) произведение. Najcelniejsi pisarze epoki. Самые выдающиеся писатели эпохи. 2. ред. Отборный: Celne nasiona. Отборные семена.

CELNY III м. (прил. $\kappa$ cto)

таможенный: Urząd celny. Таможня. Odprawa celna. Таможенный досмотр. Skład celny. Таможенный склад. Polityka celna. Таможенная политика.

2.2. Между формально сходными многозначными лексемами двух языков могут быть самые разнообразные типы отношений. При частичном совпадении семантики полисемичных слов выявляют отношения включения и пересечения (ср. напр., Rovdo 9-11). Соотношение типа $\mathbf{A} \approx \mathbf{B}$ имеет две разновидности (сp. Fedorčuk 15). В зависимости от того, на чем основывается частичное совпадение лексических значений сопоставляемых слов выделяем следующие типы формально-смысловых соответствий между русскими и польскими омопарами: 1) $\mathbf{P} \subset \boldsymbol{\Pi}$ или $\mathbf{P} \supset \boldsymbol{\Pi}$ (семантическое отношение включения: русское слово по объему лексического значения (ЛЗ) может быть больше либо меньше польского слова); 2) модель $\mathbf{P} \cap \mathbf{У}$ (семантическое отношение пересечения: в ЛЗ каждого из слов есть совпадающая часть и несовпадающие элементы). 


\subsection{1. Отношения семантического включения (модель $\mathbf{P} \subset \boldsymbol{\Pi}$ ).}

В данной модели, отношение семантического включения (где включающим является значение польского слова) наблюдается в лексических омопаpax: ДА'ВНИЙ/DAWNY и ПАМЯТКА/РАMІА̨ТКА

В русском языке ДАВНИЙ - 'бывший, происшедший задолго до настоящего момента; существующий издавна; старый, старинный’. В польском языке слово DAWNY имеет более широкое значение: помимо указанного выше значения русского слова в польском выделяются три ЛСВ 1) разг. 'непригодный для употребления; несвежий'; 2) 'такой, как был раньше; прежний, былой’; 3) 'издавна хорошо известный; древний; вчерашний, давний’

Большая широта ЛЗ польского слова позволяет говорить об отношениях включения.

Аналогичный пример: русский моносемант ПАМЯТКА формально совпадает с польским полисемантом РАМIĄTKA, однако основным значением для польского слова РАМІА̨ТКА является другой ЛСВ 'сувенир; предмет материальной культуры прошлого; памятник; память; реликвия’. Вновь русскому моносеманту соответствует двузначное польское слово, что вляется свидетельством наличия отношения включения между рассмотренными словами. Ср.:

\section{ПА'МЯТКА $\dot{z}$}

poradnik; regulamin, instrukcja: Памятка садовода. Poradnik ogrodnika.

PAMIĄTKA

сувенир; вещь, связанная с памятью о ком-л., о чём-л.: Sprzedaż pamiątek. Продажа сувениров. Pamiątka narodowa. Памятник национальной культуры. Pamiątki rodzinne. Семейные реликвии. Pamiątka po ојсu. Память об отце. $\diamond$ Na pamiątkę czegoś. В память о чём-л. $\diamond$ Dać, wziąć, przyjąć,otrzymać itp. coś na pamiątkę. Дать, взять, принять, получить и т.п. что-л. на память.

\subsection{2. Отношения семантического включения (тип $\mathbf{P} \supset \boldsymbol{\Pi})$}

Включающим в данном случае является многозначное русское слово. Так, например, русское слово КИСТЬ помимо основного значения 'часть руки от запястья до конца пальцев', а также 'скопление плодов на одной ветке; гроздь' свойственных и польской лексеме КIŚĆ, имеет еще три ЛСВ: 2) 'украшение в виде стянутого вверху пучка ниток, шнурков' Скатерть, кушак с кистями; 3) 'пучок ровных щетинок, волосков на рукоятке для нанесения краски, клея, лака' Кисти для акварели, масла; 4) перен. 'искусство живописи' Эти чарующие красоты можно передать только кистью.

Различия в подобных случаях (ДАВНИЙ - DAWNY, ПАМЯТКА - PAMIĄTKA, КИСТЬ - КIŚĆ) обусловлены наличием самостоятельных озна- 
чаемых, входящих в одном из языков в структуру многозначного слова. Подобные отношения возникают в тех случаях, когда в значении слова одного языка имеется больше семем или сем, чем в значении другого языка.

2.2.3. Как уже упоминалось, семантические различия в объемах однокорневых лексем могут быть связаны и с развитием переносных значений в одном из языков. Примером может служить межъязыковая омонимичная пара русск. БОЛЯЧКА разг. 'небольшая рана на коже; язва, опухоль, чирей' и пол. BOLĄCZKA 1) = русск. БОЛЯЧКА; 2) перен. 'трудность; проблема; больной вопрос': Bolączki społeczne. Общественные проблемы. Usuwać bolączki. Устранять трудности (проблемы).

Омонимия, на наш взгляд, возникла здесь в результате появления метафорического переноса (ЛСВ-2) в польском языке.

\section{3. Отношение семантического пересечения модель $(\mathbf{P} \cap \Pi)$}

Подобные отношения наблюдаются в тех случаях, когда значения сопоставляемых слов как бы накладываются одно на другое (то есть в них имеются совпадающие элементы), но в то же время у каждого из сопоставляемых слов остается несовпадающая семантическая часть.

Так, например, русск. БИЧ и пол. BICZ совпадают в значениях 'длинная плеть, кнут'. Однако помимо этих ЛСВ каждая из сравниваемых лексем имеет в своей структуре несовпадающие значения: в русском это еще 2) neрен. 'о том, что вызывает бедствие, несчастье': Пыльные бури - бич nycmblни. В польском же лексема BICZ приобретает дополнительные значения: 2) 'ожерелье; бусы': Bicz peret; bicz korali. Жемчужное ожерелье; коралловые бусы; 3) med. 'zabieg leczniczy' Bicz wodny.

В семантических отношениях пересечения находятся и русско-польские омонимы ЗАБАВA/ZABAWA. Русское слово совпадает с польским в основном значении - 'развлечение, игра', но различаются они другими ЛСВ. Ср. русск. ЗАБАВА 2) нар.- поэт. 'о возлюбленном или возлюбленной': Говорила моя забава, Моя, лада, любовь и слава (...) и пол. ZABAWA 2) 'собрание, на котором развлекаются, веселятся; вечеринка, танцы; бал': Noworoczna zabawa - Новогодний бал. Pójść na zabawę- Пойти (сходить) на танцы.

\section{Выводы}

Несовпадение семантических структур многозначных слов в разных языках, как известно, является одним из наиболее заметных расхождений, которое отражает существенные особенности лексических систем языков и наблюдается в различных двуязычных ситуациях. Наиболее яркие приме- 
ры различий по признаку моносемант - полисемант чаще обнаруживаются в языках, которые имеют большую родственную отдаленность.

В ходе исследования выяснилось, что межъязыковые русско-польские соответствия с частичным совпадением лексических значений составляют самую большую по количеству группу межъязыковых омопар. Семантические отношения включения могут возникать в трех случаях: 1) когда моносемант соответствует полисеманту; 2) когда соотносительные полисеманты неравнозначны по числу ЛСВ; 3) когда в одном из соотносительных слов развивается переносные значения.

Анализ семантических отношений в сфере русско-польской межъязыковой омонимии позволил выявить две основные причины расхождения семантики слов обоих языков:

- как следствие семантической дивергенции, т. е. расхождения значений одного и того же слова (распад полисемии, расширение/сужение семантических объемов);

- как следствие конвергентного развития форм разных по происхождению слов (т. н. случайные омонимы).

Типы семантических реляций, описанные на уровне слова, не исчерпывают многообразия семантических отношений между русско-польскими межъязыковыми омонимами. Глубина разработки значения - еще одна теоретическая проблема современной лексикологии и лексикографии. Помимо собственно семантических различий между русско-польскими омопарами могут существовать более сложные отношения (Norman 132). Они наблюдаются в тех случаях, когда на смысловые несоответствия наслаиваются стилистические и функциональные расхождения. Различия по прагматическому значению являются наиболее значительными и могут составить предмет самостоятельного изучения.

\section{Библиография}

Balalykina, Èmiliâ. „Ėnantiosemiâ kak leksiko-grammatičeskoe âvlenie”. Przegląd Rusycystyczny, $1-2,1985$, s. $75-84$.

Dubičinskij, Volodymyr. Russko-anglijskie leksičeskie paralleli. Har'kov, Har'kovskoe leksikografičeskoe obŝestvo, 1993.

Fedorčuk, Elena. Mež"âzykovye omonimy $i$ paronimy v blizkorodstvennyh âzykah (na materiale russkogo i ukrainskogo âzykov). Moskva, Izd-tvo MPGU, 2001.

Karpov, Vladimir. „Vnutriâzykovaâ i mež"âzykovaâ omonimiâ bolgarskogo âzyka”. Slavističeskij sbornik. Red. German I. Safronov, Galina A. Lilič. Sankt-Peterburg, Izdatel'stvo SPBGU, 1998, s. 56-63.

Kusal, Krzysztof. Vosproizvedenie i vospriâtie russkih zvukotipov v inostrannoj auditorii. Wrocław, Wydawnictwo Uniwersytetu Wrocławskiego, 1998. 
Kusal, Krzysztof. Rosyjsko-polski słownik homonimów międzyjęzykowych//Russko-pol'skij slovar' mež"âzykovyh omonimov. Wrocław, Wydawnictwo Uniwersytetu Wrocławskiego, 2002.

Lejčik, Vladimir. „Tipologiâ omonimov i paronimov”. Stupskie Prace Humanistyczne, 18, 1999.

Lipczuk, Roman. „O różnicach semantycznych w zakresie niektórych tautonimów czasownikowych w relacji niemiecko-polskiej”. Języki Obce w Szkole, 5, 1988.

Malahovskij, Lev. Teoriâ leksičeskoj i grammatičeskoj omonimii. Leningrad, Nauka, 1990.

Norman, Boris. „O nekotoryh aspektah mež"âzykovoj omonimii”. Polonistika 2002/2003. Minsk, 2004.

Plotnikov, Boris. „O mež"âzykovoj sinonimii i antonimii (na materiale slavânskih âzykov)”. Voprosy obŝestvennyh i gumanitarnyh nauk. Materialy II naučno-metodičeskoj konferencii. Gomel', 1974.

Rovdo, Ivan. Mež"âzykovaâ omonimiâ v usloviâh russko-belorusskogo i belorussko-russkogo bilingvizma. Minsk, Izd-vo BGU, 1980.

Suprun, Adam. „Nekotorye problemy prepodavaniâ russkogo âzyka v usloviâh blizkorodstvennogo dvuâzyčiâ". RÂAŠ, 4, 1975.

Zinkevič, Andrej. „Differencial'nyj slovar' - pohožee v nepohožem”. II Slavističeskie čteniâ pamâti prof. P. A. Dmitrieva i prof. G. I. Safronova. Materialy meždunarodnoj naučnoj konferencii 12-14 sentâbrâ Sankt-Peterburg 2000 g. Sankt-Peterburg, Izdatel'stvo SPBGU, 2001. 